\title{
Analisis Indeks Preventive Maintenance Peralatan Medis Ruang Intensive Care Unit Menggunakan Model Kano dan Quality Function Deployment
}

\author{
*Arierta Pujitresnani ${ }^{1)}$, Mulyatno ${ }^{2)}$
}

Program Studi DIV Teknik Elektromedik, Fakultas Kesehatan, Universitas Mohammad Husni Thamrin

Corresponden author: arierta.p@gmail.com

Received : 20 April $2021 \quad$ Accepted : 24 September 2021

Published: 30 September 2021

DOI: https://doi.org/10.37012/jik.v13i2.407

\begin{abstract}
ABSTRAK
Manajemen preventive maintenance (PM) alat medis ruang Intensive Care Unit (ICU) di rumah sakit sangat penting dilakukan oleh teknisi elektromedik dalam memastikan fungsinya sebagai alat penunjang hidup dapat bekerja dengan baik. Hal tersebut menjadi alasan perlunya dilakukan penelitian ini agar dapat memberikan rekomendasi kepada manajemen rumah sakit berdasarkan penilaian yang obyektif dan terkuantisasi. Tujuan dari penelitian ini untuk mengetahui skala Indeks Prioritas Preventive Maintenance (IPPM) alat medis ruang ICU menggunakan metode pendekatan pemodelan Kano dan Quality Function Deployment (QFD). Dari hasil analisis model Kano yang diintegrasikan dengan model House of Quality (HOQ) pada metode QFD diketahui bahwa faktor keselamatan pasien dan ketersediaan alat medis yang berfungsi dengan baik merupakan kebutuhan esensial yang harus terpenuhi. Salah satu cara untuk mencapainya adalah dengan manajemen PM sesuai dengan skala IPPM. Berdasarkan domain fungsi dan konsep pada metode pendekatan QFD didapatkan bahwa alat medis di ruang ICU masuk dalam kategori berdasarkan risiko $(\mathrm{R})$ dengan 3 ranking tertinggi masing-masing untuk kriteria kebutuhan maintenance $(\mathrm{R}=1)$, risiko fisik $(\mathrm{R}=2)$, fungsi $(\mathrm{R}=3)$ dan ventilator mendapat nilai prioritas ( $\mathrm{PS}=90 \%)$ yang masuk dalam group I. Dari data tersebut dapat disimpulkan bahwa peralatan medis di ruangan ICU khususnya ventilator memiliki IPPM yang tinggi dan perlu penjadwalan serta pencatatan yang baik.
\end{abstract}

Kata Kunci : Intensive Care Unit (ICU), Model Kano, Preventive Maintenance, Quality Function Deployment (QFD).

\begin{abstract}
Management of preventive maintenance (PM) for medical devices in the Intensive Care Unit (ICU) of hospitals is very important for electromedical technicians to ensure that life support equipment can work properly. This is the background of the research in order to provide recommendations to hospital management based on objective and quantized assessments. The purpose of this study was to determine the scale of the Preventive Maintenance Priority Index (IPPM) for medical devices in the ICU using the Kano modeling and Quality Function Deployment (QFD). From the results of the Kano model analysis which is similar to the concept of the House of Quality (HOQ) QFD domain model, it is known that the patient safety factor and the availability of medical devices that work well are essential needs that must be met. One way to achieve that by PM management according to the IPPM scale. Based on the domain functions and concepts in the QFD approach method, it was found that medical devices in the ICU were included in the category based on risk $(R)$ with the 3 highest ranks respectively for the criteria of maintenance needs $(R=1)$, physical risk $(R=2)$, functional $(R=3)$ and the ventilator received a priority score $(P S=90 \%)$ which was included in group I. From these data, it can be ascertained that the medical equipment in the ICU, especially the ventilator, has a high IPPM and requires good scheduling and recording.
\end{abstract}

Keywords: Intensive Care Unit (ICU), Canoe Model, Preventive Maintenance, Quality Function Deployment $(Q F D)$ 


\section{PENDAHULUAN}

Peralatan kesehatan adalah salah satu faktor penting dalam pelayanan kesehatan kepada masyarakat. Pelayanan kesehatan yang berkelanjutan perlu didukung dengan peralatan yang selalu dalam kondisi laik pakai dan dapat difungsikan dengan baik. (Direktorat Jendral Pelayanan Medik, 2001)

Alat kesehatan didefinisikan sebagai alat yang digunakan untuk mencegah, mendiagnosis, menyembuhkan, dan meringankan penyakit, merawat, memulihkan kesehatan, membentuk struktur dan memperbaiki fungsi tubuh. (Jamshidi et al., 2014)

Menurut penelitian (Janahar, 1991) tentang Sistem Monitoring Efek Pengamanan Alat Kesehatan, dari 63 persen alat kesehatan yang bermasalah maka 10 persennya merupakan alat kesehatan yang rusak. Peralatan kesehatan yang seringkali mengalami kerusakan dicontohkan sebagai berikut : (1) alat tensimeter yang sering macet Ketika digunakan akan mengakibatkan hasil pengukuran yang didapat menjadi tidak tepat dan akan mempengaruhi pemberian obat, (2) alat bedah listrik terkadang dapat menyebabkan kulit terbakar saat digunakan selama operasi, (3) alarm dan signal pada alat bantu pernafasan terganggu akibat adanya perubahan tegangan listrik, (4) elektrokardiograf / EKG yang tidak pernah dilakukan kalibrasi dapat menghasilkan pengukuran tidak akurat serta sulit dipercaya (Cruz et al., 2013), dan (5) ultrasonografi / USG yang ada di bagian radiologi dengan pemakaian selama 6 bulan menghasilkan gambar yang sudah tidak jelas lagi.

Berbagai permasalahan di atas dapat terjadi dikarenakan manajemen pemeliharaan alat medis tidak berjalan dengan baik. Dapat dibayangkan jika masalah-masalah tersebut terjadi dalam area kritis ruang Intensive Care Unit (ICU) di rumah sakit, dimana beberapa alat medis yang digunakan merupakan alat penunjang hidup pasien maka kualitas pelayanan rumah sakit akan sangat buruk.

Oleh karena itu, untuk mencegah beberapa permasalahan di atas maka perlu dilakukan evaluasi pelaksanaan pemeliharaan peralatan medis di rumah sakit menggunakan pendekatan model Kano, yaitu analisis pemenuhan kepuasan pelanggan serta diintegrasikan dengan Quality Function Deployment (QFD) yang merupakan suatu instrumen kuantitatif untuk analisis kualitas manajemen pemeliharaan peralatan medis dalam memenuhi kebutuhan pelanggan. Hal ini bertujuan untuk meningkatkan kualitas pelayanan rumah sakit khususnya di ruangan Intensive Care Unit (ICU) rumah sakit. 


\section{METODE}

Penelitian ini merupakan jenis penelitian kualitatif menggunakan user-based approach untuk mengukur kualitas pelayanan teknisi elektromedik di rumah sakit (performance in house maintenance) dan kuantitatif pengolahan data menggunakan instrumen Quality Function Deployment (QFD) yang diterapkan sebagai model referensi sistem pemeliharaan peralatan medis di rumah sakit. Penelitian dilakukan di Rumah Sakit X Jakarta Pusat selama 9 Bulan mulai Februari sampai dengan Oktober 2020. Populasi penelitian adalah seluruh perawat yang berada di ruang Intensive Care Unit (ICU). Sedangkan sampel penelitian adalah perawat yang bertugas sebagai operator peralatan medis atau pengguna peralatan medis di ruang Intensive Care Unit (ICU). Teknik pengambilan sampel dalam penelitian ini menggunakan metode purposive sampling dengan rumus Slovin sejumlah 30 responden. Teknik pengumpulan data dalam penelitian ini menggunakan metode survey melalui instrumen penelitian berupa kuesioner dan wawancara kepada operator peralatan medis atau pengguna peralatan medis di ruang Intensive Care Unit (ICU).

Pengolahan data menggunakan komputer yang dilengkapi dengan software SPSS.22 untuk mengolah data dan menilai hasil kuesioner kepuasan pengguna peralatan medis pada model Kano. Langkah awal untuk mendapatkan atribut-atribut kuesioner sebagai instrumen penelitian dengan melakukan penjaringan voice of customer (VOC). Berdasarkan voice of customer (VOC) tersebut dapat diidentifikasi keluhan dan saran dari responden sebagai pengguna peralatan medis terhadap pelayanan yang diberikan oleh teknisi elekromedik di rumah sakit. Dari hasil pengolahan data akan dilakukan analisa pengklasifikasian kategori dengan model Kano yang diintegrasikan dengan model House Of Quality (HOQ) pada metode Quality Function Deployment (QFD) untuk masing-masing atribut keinginan pengguna peralatan medis di rumah sakit dalam rangka mengetahui atribut mana yang paling berpengaruh atau dominan terhadap kepuasan dan ketidakpuasan pengguna peralatan medis di rumah sakit. Setelah mendapat perolehan hasil analisa tersebut, selanjutnya memasuki tahap perancangan kualitas layanan dengan menentukan skala Indeks Prioritas Preventive Maintenance (IPPM) untuk masing-masing peralatan medis di ruang Intensive Care Unit (ICU) yang mengacu pada penilaian parameter dalam metode Quality Function Deployment (QFD). 


\section{HASIL DAN PEMBAHASAN}

Hasil analisa pengklasifikasian kategori dengan model Kano yang diintegrasikan dengan model House Of Quality (HOQ) pada metode Quality Function Deployment (QFD) diketahui bahwa factor yang paling berpengaruh atau dominan dan harus terpenuhi demi kepuasan pengguna peralatan medis di rumah sakit adalah faktor keselamatan pasien dan ketersediaan alat medis yang berfungsi dengan baik. (Materla et al., 2019)

Selain itu didapatkan hasil data untuk 4 kriteria dari technical requirements antara lain risiko $(\mathrm{R})$, performance $(\mathrm{P})$, kompetensi $(\mathrm{K})$, dan standar $(\mathrm{S})$ yang memiliki indeks prioritas tertinggi adalah kriteria risiko (R). (Harijith \& Naduthodi, 2017) Sedangkan untuk kriteria risiko $(\mathrm{R})$ itu sendiri terdiri dari 3 parameter yang memilki skor tertinggi, yaitu parameter fungsi peralatan $(\mathrm{R}=1)$, kritis $(\mathrm{R}=2)$, kebutuhan maintenance $(\mathrm{R}=3)$. Sehingga area Intensive Care Unit (ICU) menjadi paling dominan untuk ditetapkan sebagai Indeks Prioritas Preventive Maintenance (IPPM).

Dalam menentukan skala Indeks Prioritas Preventive Maintenance (IPPM) untuk masingmasing peralatan medis di ruang Intensive Care Unit (ICU) dilakukan penilaian skor mengacu pada 11 (sebelas) parameter yang terdaftar pada Tabel 1. (Saleh et al., 2014) Sebelas parameter tersebut terpilih berdasarkan prioritas dan kepentingannya serta diuraikan dengan kriteria batas acuan masing-masing untuk menentukan penilaian yang disesuaikan pada peralatan medis di ruang Intensive Care Unit (ICU).

Tabel 1.

Deskripsi Singkat Parameter Kritis dan Skor yang Diusulkan

\begin{tabular}{|c|c|c|c|}
\hline Parameter & Description & Thresholds & Scores \\
\hline \multirow{5}{*}{ Function } & \multirow{5}{*}{ Device function } & Life support & 5 \\
\hline & & Therapeutic & 4 \\
\hline & & Diagnostic/monitoring & 3 \\
\hline & & Analytical & 2 \\
\hline & & Miscellaneous & 1 \\
\hline \multirow{5}{*}{ Physical risk } & \multirow{5}{*}{$\begin{array}{l}\text { Probable harms caused by } \\
\text { equipment failure }\end{array}$} & Death & 5 \\
\hline & & Injury & 4 \\
\hline & & Misdiagnosis & 3 \\
\hline & & Equipment damage & 2 \\
\hline & & No risk & 1 \\
\hline \multirow{5}{*}{$\begin{array}{l}\text { Maintenance } \\
\text { requirements }\end{array}$} & \multirow{5}{*}{$\begin{array}{l}\text { Maintenance activities } \\
\text { depending on equipment type }\end{array}$} & Extensive & 5 \\
\hline & & A above average & 4 \\
\hline & & Average & 3 \\
\hline & & Below average & 2 \\
\hline & & Minimal & 1 \\
\hline \multirow{3}{*}{ Utilization level } & \multirow{3}{*}{ Number of working days a week } & 4 days & 3 \\
\hline & & $3 / 4$ days & 2 \\
\hline & & $<3$ days & 1 \\
\hline
\end{tabular}




\begin{tabular}{|c|c|c|c|}
\hline Area criticality & $\begin{array}{l}\text { Assessment of area criticality } \\
\text { for patiens }\end{array}$ & $\begin{array}{c}\text { Urgent } \\
\text { Intensity care unit } \\
\text { Diagnostic area } \\
\text { Law intensity area } \\
\text { Non clinical area } \\
\end{array}$ & $\begin{array}{l}5 \\
4 \\
3 \\
2 \\
1\end{array}$ \\
\hline Device criticality & $\begin{array}{l}\text { The importance level of } \\
\text { equipment in serviced area }\end{array}$ & $\begin{array}{c}\text { Critical } \\
\text { Important } \\
\text { Necessary }\end{array}$ & $\begin{array}{l}3 \\
2 \\
1\end{array}$ \\
\hline Failure rate & $\begin{array}{l}\text { Number of failures a year based } \\
\text { on device criticality level }\end{array}$ & $\begin{array}{c}\geq 2 \text { for critical, } \geq 4 \text { for } \\
\text { important, } \geq 5 \text { for } \\
\text { necessary } \\
1 \text { for critical, } 2 / 3 \text { for } \\
\text { important, } 3 / 4 \text { for necessary } \\
0 \text { for critical, } \leq 1 \text { for } \\
\text { important, } \leq 2 \text { for } \\
\text { necessary }\end{array}$ & 1 \\
\hline Useful life ratio & $\begin{array}{l}\text { Ratio between age to expected } \\
\text { life time of a device }\end{array}$ & $\begin{array}{c}\text { Ratio }>80 \% \\
50 \%<\text { Ratio } \leq 80 \% \\
\text { Ratio } \leq 50 \%\end{array}$ & $\begin{array}{l}3 \\
2 \\
1\end{array}$ \\
\hline $\begin{array}{l}\text { Device } \\
\text { complexity }\end{array}$ & $\begin{array}{l}\text { Technical complexity based on } \\
\text { a model }\end{array}$ & $\begin{array}{l}\text { Score 6-8 } \\
\text { Score 3-5 } \\
\text { Score 0-2 } \\
\end{array}$ & $\begin{array}{l}3 \\
2 \\
1 \\
\end{array}$ \\
\hline $\begin{array}{l}\text { Missed } \\
\text { maintenance }\end{array}$ & $\begin{array}{l}\text { Number of missed maintenance } \\
\text { a year }\end{array}$ & $\begin{array}{c}\geq 2 \\
1 \\
0\end{array}$ & $\begin{array}{l}3 \\
2 \\
1 \\
\end{array}$ \\
\hline Downtime ratio & $\begin{array}{l}\text { Ratio between the duration of } \\
\text { downtime in days to days a year }\end{array}$ & $\begin{array}{c}\text { Ratio } \geq 20 \% \\
10 \%<\text { Ratio }<20 \% \\
\text { Ratio }<10 \%\end{array}$ & $\begin{array}{l}3 \\
2 \\
1\end{array}$ \\
\hline
\end{tabular}

Nilai parameter yang sudah ditentukan untuk masing-masing peralatan medis dan terdaftar pada Tabel 2 kemudian dikalkulasi menggunakan persamaan formula (1) sehingga menghasilkan skala Indeks Prioritas Preventive Maintenance (IPPM) peralatan medis di ruang Intensive Care Unit (ICU).

$$
\begin{aligned}
\mathrm{PS}= & 11.7(\mathrm{FN})+12.8(\mathrm{PR})+20.4(\mathrm{MR})+11(\mathrm{UL})+6.5(\mathrm{AC})+11.4(\mathrm{DC}) \\
& +8.3(\mathrm{FR})+5.1(\mathrm{LR})+6.3(\mathrm{CM})+3.4(\mathrm{MM})+3.1(\mathrm{DR})
\end{aligned}
$$

dimana

PS priority score;

FN function of equipment;

PR physical risk;

MR maintenance requirement;

UL utilization level;

AC area criticality;

DC device criticality;

FR failure rate; 


\section{LR useful life ratio;}

$\mathrm{CM}$ device complexity;

MM missed maintenance;

DR downtime ratio.

Tabel 2.

Sampel Data Peralatan medik berdasarkan Indeks Prioritas Maintanance

\begin{tabular}{lccccccccccccc}
\hline Equipment & FN & PR & MR & UL & AC & DC & FR & LR & CM & MM & DR & PS & PS\% \\
\hline Ventilator & 5 & 5 & 5 & 2 & 5 & 3 & 2 & 3 & 3 & 3 & 1 & 300 & 90 \\
Pasien Monitor & 3 & 3 & 4 & 2 & 5 & 3 & 3 & 3 & 3 & 2 & 2 & 290 & 78 \\
Syringe Pump & 3 & 3 & 3 & 3 & 3 & 2 & 3 & 3 & 2 & 1 & 1 & 150 & 66 \\
EKG & 2 & 3 & 3 & 3 & 2 & 2 & 1 & 3 & 1 & 1 & 1 & 250 & 56 \\
Defibrilator & 1 & 1 & 1 & 1 & 3 & 1 & 1 & 2 & 1 & 2 & 1 & 280 & 30 \\
\hline
\end{tabular}

Data pada Tabel 2 adalah untuk 6 (enam) peralatan medis yang berada di ruang Intensive Care Unit (ICU), yaitu ventilator, pasien monitor, syringe pump, elektrokardigram (EKG), dan defibrilator yang masing-masing dilakukan penilaian dengan skala 1-5 terhadap 11 (sebelas) parameter seperti pada Tabel 1. Ke-11 parameter tersebut yaitu FN (function of equipment), PR (physical risk), MR (maintenance requirement), UL (utilization level), AC (area criticality), DC (device criticality), FR (failure rate), LR (useful life ratio), CM (device complexity), MM (missed maintenance), DR (downtime ratio). Nilai dari seluruh parameter tersebut kemudian dihitung menggunakan formula (1) hingga didapatkan PS (priority score) untuk setiap peralatan medis di ruang Intensive Care Unit (ICU). Ventilator memiliki $\mathrm{PS}=90 \%$, pasien monitor memiliki $\mathrm{PS}=78 \%$, syringe pump memiliki PS=66\%, elektrokardigram $(\mathrm{EKG})$ memiliki $\mathrm{PS}=56 \%$, dan defibrillator memiliki PS=30\%.

\begin{tabular}{|c|c|}
\hline Group I & - Very high priority (PS $\geq 80 \%)$ \\
\hline Group II & - High priority ( $70 \% \leq \mathrm{PS}<80 \%)$ \\
\hline Group III & - Medium priority $(60 \% \leq \mathrm{PS}<70 \%)$ \\
\hline Group IV & - Low priority ( $50 \% \leq \mathrm{PS}<60 \%)$ \\
\hline Group V & - Minimal priority (PS $<50 \%)$ \\
\hline
\end{tabular}

Gambar 1. Group Indeks Prioritas Maintanance Berdasarkan Prioritas Skor (PS) (Saleh et al., 2014)

Jika dilihat dari hasil PS peralatan medis pada Tabel 2 maka didapatkan skala Indeks Prioritas Preventive Maintenance (IPPM) peralatan medis di ruang Intensive Care Unit (ICU) rumah sakit yang memiliki skor prioritas tertinggi adalah alat ventilator yaitu dengan PS=90\% (kategori group I: PS $\geq 80 \%$ ). Sehingga alat ini ditetapkan sebagai alat yang paling tinggi 
indeks prioritasnya untuk dilakukan perawatan dan pemeliharaan peralatan medis di rumah sakit.

\section{SIMPULAN DAN REKOMENDASI}

Faktor keselamatan pasien dan ketersediaan alat medis yang berfungsi dengan baik merupakan kebutuhan esensial yang harus terpenuhi demi memenuhi kepuasan pengguna peralatan medis di ruang Intensive Care Unit (ICU) dalam hal ini adalah pasien dan staf klinis berdasarkan penilaian analisis menggunakan model kano yang diintegrasikan dengan model House of Quality (HOQ) pada metode Quality Function Deployment (QFD). Selain itu dapat diketahui pula bahwa kriteria berbasis risiko memiliki pengaruh besar pada keputusan prioritas preventif maintenance selain tingkat kekritisan dan usia peralatan medis di rumah sakit. Salah satunya alat ventilator yang memiliki skor prioritas tertinggi untuk dilakukan perawatan dan pemeliharaan peralatan medis di rumah sakit

Sehingga kami rekomendasikan perlu dibuat sistem pencatatan riwayat perawatan seluruh peralatan medis di rumah sakit khsususnya di ruang Intensive Care Unit (ICU) untuk memudahkan manajemen dalam memutuskan kebijakan dan mengelola peralatan medis secara jelas.

\section{REFERENSI}

1. Cruz, A. M., Rincon, A. M. R., \& Haugan, G. L. (2013). Measuring the performance of maintenance service outsourcing. Biomedical Instrumentation \& Technology, 47(6), 524-535. https://doi.org/10.2345/0899-8205-47.6.524

2. Direktorat Jendral Pelayanan Medik. (2001). Pedoman Operasional Pemeliharaan Peralatan Kesehatan.

3. Harijith, R. G., \& Naduthodi, H. (2017). Kano Model Customer Satisfaction Analysis of Medical Services. International Research Journal of Engineering and Technology(IRJET), 4(6), 1426-1429. https://irjet.net/archives/V4/i6/IRJETV4I6263.pdf

4. Jamshidi, A., Rahimi, S. A., Ait-Kadi, D., \& Bartolome, A. R. (2014). Medical devices inspection and maintenance: a literature review. IIE Annual Conference and Expo 2014, 3895-3904. 
5. Janahar. (1991). Penelitian Sistem Monitoring Efek Pengamanan Alat Kesehatan.

6. Materla, T., Cudney, E. A., \& Antony, J. (2019). The application of Kano model in the healthcare industry: a systematic literature review. Total Quality Management \& Business $\quad$ Excellence, 30(5-6), 660-681. https://doi.org/10.1080/14783363.2017.1328980

7. Saleh, N., Sharawi, A., Wahed, M., Petti, A., Puppato, D., \& Balestra, G. (2014). Preventive Maintenance Prioritization Index of Medical Equipment Using Quality Function Deployment. IEEE Journal of Biomedical and Health Informatics, 19. https://doi.org/10.1109/JBHI.2014.2337895 